\title{
Textile dyes induce toxicity on zebrafish early life stages/early developmental stages
}

Running title: Textile dyes induce toxicity on zebrafish early life stages

Gisele Augusto Rodrigues de Oliveira ${ }^{\dagger} \S^{*}$, Joaquín de Lapuente ${ }^{\ddagger}$, Elisabet Teixidó ${ }^{\ddagger}$, Constança Porredón ${ }^{\star}$, Miquel Borràs ${ }^{\star}$, Danielle Palma de Oliveira ${ }^{\S}$

${ }^{\dagger}$ FF-UFG, Laboratory of Toxicology, Faculty of Pharmacy, Federal University of Goiás, 74605-170, Goiânia, Goiás, Brazil.

${ }^{\ddagger}$ UTOX-PCB, Unit of Experimental Toxicology and Ecotoxicology, Barcelona Science Park, 08028, Barcelona, Spain.

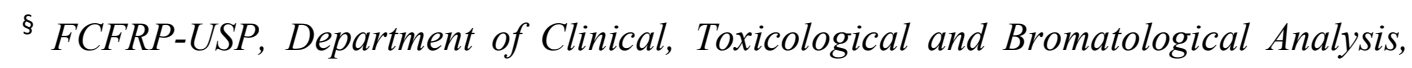
Faculty of Pharmaceutical Sciences at Ribeirão Preto, University of São Paulo, 14040903, Ribeirão Preto, São Paulo, Brazil. 
*Corresponding author: Gisele Augusto Rodrigues de Oliveira

e-mail: gisele23.rodrigues@hotmail.com / gaugusto@ufg.br

Address correspondence: Rua 240, s/n, Setor Leste Universitário, 74605-170, Goiania/Goias, Brazil.

Tel.: +55 623609 6450; Fax: +5562 32096037 


\begin{abstract}
Textile manufacturing is one of the most polluting industrial activities not only because the large amount of water used during the process, but also due to the release of potentially toxic compounds, such as synthetic dyes. Due to consumer's desire for color stability of the fibers during washing, perspiration and sun exposure, textile dyes have very stable chemical structure, thus they are difficult to be degraded. Depending on the class of the dyes, their loss in wastewaters can range from $2 \%$ of the original concentration for basic dyes to as high as $50 \%$ for reactive dyes. Therefore, unlimited and uncontrolled use of such dyes can lead to serious consequences for human health and ecological balance. This study assessed the lethal and sublethal effects of the textile dyes Direct Black 38 (DB38), Reactive Blue 15 (RB15), Reactive Orange 16 (RO16), and Vat Green 3 (VG3) on zebrafish embryos (Danio rerio) for $144 \mathrm{~h}$ post-fertilization (hpf). Neither of the studied dyes induced significant mortality at 8, 24, and $48 \mathrm{hpf}$. The highest RO16 dose significantly delayed or inhibited the ability of zebrafish embryos to hatch from the chorion after 96 hpf. All dyes caused defects in the gas bladder inflation of zebrafish larvae from 120 to $144 \mathrm{hpf}$. In this exposure period, higher doses of DB38 also induced curved spine, whereas VG3 led to yolk sac edema in zebrafish larvae. Based on the present data, we concluded that the textile dyes DB38, RB15, RO16, and VG3 induce malformation during the embryonic and larval development of zebrafish, thus effluents discharge containing these compounds into water bodies should be prevented.
\end{abstract}

Keywords: aquatic toxicology, contaminants of emerging concern, developmental toxicity, ecotoxicology, ecological risk assessment, azo dyes, malformations, alternative to animal testing. 


\section{INTRODUCTION}

Synthetic dyes have increasingly been used in the textile and dyeing industries because of their ease and cost-effectiveness in synthesis, firmness, high stability to light, temperature, detergent and microbial attack and variety in color, when compared with natural dyes [1]. Based on the chemical structure of the chromophoric group, synthetic dyes are classified into azo, nitro, anthraquinone, triarylmethane, xanthene, heterocyclic, or indigo dyes. According to the means of application in the fiber, they can belong to the classes of reactive, acid, direct, basic, mordant, disperse, pigment, vat, anionic and ingrain, sulphur, solvent, disperse and azoic dye $[2,3]$.

In recent years, textile dyes are widely used all over the world, and textile industry plays an important role in nation's economy [4]. However, dyes have generated much concern regarding their use, due to the reported toxic effects. Additionally, textile manufacturing consumes a considerable amount of water during the industrial processes, generating large quantities of textile wastewaters, which are discharged with dyes and other undesirable chemicals [5,6]. The amount of dye directly lost to the wastewater is dependent on the class of dye applied, varying from only $2 \%$ loss when using basic dyes to $50 \%$ loss when certain reactive dyes are used [6-8].

Due to their chemical structure, dyes are resistant to chemical, physical, and biological treatments. In fact, many dyes are difficult to decolorize due to their complex structure and synthetic origin [6,9]. Thus, the discharge of these compounds into the environment is undesirable not only for esthetic reasons but also because many dyes and their byproducts are toxic to both aquatic life and humans [4,10-14].

Considering the environmental impact caused by the discharge of these compounds, this study investigated the dyes Direct Black 38, Reactive Blue 15, 
Reactive Orange 16, and Vat Green 3, as models to evaluate aquatic toxicity induced by synthetic dyes.

Direct dyes are the most popular class of dyes with easy application, wide color range, and available low cost. Direct Black 38 (DB38) is a benzidine-based azo dye, classified as carcinogenic by the International Agency for Research on Cancer (IARC) $[15,16]$ due to its biotransformation to benzidine [17]. Most direct dyes have disazo and trisazo structures. Azo dyes are the largest class (60-70\%) of dyes with the greatest variety of colors. The ubiquitous use makes them widely spread in aquatic systems, with great potential to bring adverse effects on aquatic environment [4].

Reactive dyes are frequently used in textile industries, specifically in cotton dyeing [6]. According to literature, Reactive Blue 15 (RB15), a copper-phtalocyanine dye, is moderately genotoxic for tadpoles Rana hexadactyla [18] and toxic for Vibrio fischeri [19]. Novotny et al. [20] have also observed that monoazo Reactive Orange 16 (RO16) dye induces point mutations in TA98 and TA100 strains of Salmonella typhimurium after metabolic activation.

Vat dyes, which include indigo and anthraquinone-based dyes, are chemically complex compounds insoluble in water, which can be reduced into their leuco form by alkaline solution of sodium hydrosulfite before application to cotton and polymeric fibers [21,22]. Vat Green 3 (VG3), an anthraquinone dye, is extremely toxic to the aquatic organisms Daphnia similis, Ceriodaphnia dubia and Pseudokirchneriella subcapitata [23].

Therefore, according to the toxicological studies, several textile dyes and textile effluents may affect the aquatic ecosystem, due to their toxic effects on Artemia $s p$ [24,25] Vibrio fischeri [20,24,26], green algae [20, 23], Daphnia magna [24,27,28], 
Daphnia similis $[14,23]$, and fish $[4,24,29,30]$. However, to date, there is no information about the effects of these compounds on fish embryos.

This is the first study on the effects of textile dyes on zebrafish early life stages. Zebrafish (Danio rerio) is a small freshwater tropical fish native to the rivers of India and South Asia, with a short lifecycle, high fecundity, short reproduction cycle, and with high number of eggs per spawning. Additionally, it has a rapid development and transparent eggs, which allow visualizing its development [31-33]. This kind of fish has become one of the most important model organisms in developmental biology of vertebrates and toxicology studies. Moreover, experiments with embryos are considered as refinement to animal experiments, and offer a multicellular system integrating the interaction of various tissues and differentiation processes, when compared to experiments with cell lines [32,34].

In this context, the developmental toxicity of textile dyes in zebrafish early life stages was investigated. For that, zebrafish embryos/larvae were exposed to different concentrations of Direct Black 38, Reactive Blue 15, Reactive Orange 16, and Vat Green 3 dye, to clarify any differences in sensitivity to the adverse effects of these classes of dye during development. Mortality, hatching rates, and malformations at different developmental stages attributed to the dyes exposure were observed and analyzed.

\section{MATERIAL AND METHODS}

\subsection{Test compounds}

The dyes Direct Black 38 (DB38; Chlorazol Black E; purity $\geq 45 \%$; CAS No. 1937-37-7), Reactive Blue 15 (RB15; Turquoise Blue; purity 35\%; CAS No.: 12225-397), Reactive Orange 16 (RO16; Remazol Brilliant Orange 3R; purity 50\%; CAS No.: 
12225-83-1) were purchased from Sigma (St Louis, MO, USA) and Vat Green 3 (VG3; Indanthrene Olive Green B; CAS No.: 69500) was gently donated by Dystar (Brazil). The chemical structure of each dye is presented in Figure 1. In this study, dyes will be grouped according to their application class.

\subsection{Embryo-larval toxicity test}

\subsubsection{Maintenance of zebrafish and acquisition of eggs}

Adult male and female zebrafish (Danio rerio) were obtained from a commercial supplier (Pisciber, Barcelona) and kept separately in a closed flow-through system in reconstituted water in accordance with ISO standard 7346-1 [35] $\left(2 \mathrm{mM} \mathrm{CaCl}_{2} \cdot 2 \mathrm{H}_{2} \mathrm{O}\right.$; $0.5 \mathrm{mM} \mathrm{MgSO} 4.7 \mathrm{H}_{2} \mathrm{O} ; 0.75 \mathrm{mM} \mathrm{NaHCO}$; $\left.0.07 \mathrm{mM} \mathrm{KCl}\right)$. The criterium for fish keeping was temperature of $26 \pm 1^{\circ} \mathrm{C}$ at a $14 / 10 \mathrm{~h}$ light/dark photoperiod. Fish were fed with commercial dry flake food and live brine shrimp.

For the acquisition of eggs, adult zebrafish male:female ratio of 2:1 was placed in breeding tanks (Aquaneering, San Diego, California) the day before spawning. Plastic plants served as a spawning substrate and were fixed to the bottom grid to prevent predation of eggs by adult zebrafish. About 30 minutes after beginning of spawning (triggered by sudden illumination of the aquaria on the next morning), the spawn traps were removed and the eggs were collected using plastic disposable pipettes. Eggs were transferred immediately to Petri dishes and successively cleaned with water dilution corresponding to the reconstituted water, according to ISO-standard [35], which was diluted 1:5 with deionized water. All eggs were examined under a dissecting microscope. Then, the unfertilized eggs were discarded and those embryos exhibiting normal development that had reached the blastula stage were selected for subsequent experiments. 


\subsubsection{Embryo exposure}

Direct Black 38, Reactive Blue 15, and Reactive Orange 16 dyes were prepared with water dilution corresponding to the reconstituted water, according to ISO-standard [35]. Vat Green 3 dye was dissolved in reconstituted water ISO-standard [35] 1:5 using deionized water. The tests were carried out using five different concentrations of each dye and positive or solvent controls. Doses were established according to OECD draft guideline on Fish Embryo Toxicity (FET) Test [36], and determined in at least one previous range-finding assay or lethality test with a limit concentration at $100 \mathrm{mg} / \mathrm{L}$ (data not shown).

At 4 hours post-fertilization (hpf), 10 fertilized eggs per concentration were randomly selected and carefully distributed to a 24-well plate, filled with $2 \mathrm{~mL}$ of each dye solution as follows: Direct Black 38 (1.56, 3.12, 6.25, 12.5 and $25 \mathrm{mg} / \mathrm{L})$, Reactive Blue 15, Reactive Orange 16 and Vat Green 3 at $6.25,12.5,25,50$, and $100 \mathrm{mg} / \mathrm{L}$. The tests were performed in triplicate in a climate chamber at $27 \pm 1{ }^{\circ} \mathrm{C}$ on a 14 -h light and 10-h dark cycle. The exposure of embryos was static. Neither food nor aeration was provided during the bioassays.

\subsubsection{Selected endpoints}

Fish embryo test was carried out according to the protocols described by Nagel [37] and OECD Guideline TG 212 [38], with slight modifications. The embryo test procedure was prolonged until $144 \mathrm{hpf}$ to evaluate the hatching rate, besides the evidence of delayed effects found in the initial-range finding experiments. Embryo development was assessed at 8, 24, 72, 96, 120, and $144 \mathrm{hpf}$, using a stereomicroscope (SMZ-168, Motic). The evaluated endpoints in this study are shown in Table 1. Mortality was identified by coagulation of embryos, no somite formation, non- 
detachment of the tail, as well as lack of heart-beat. Survival and malformation of larvae were observed and recorded every day after hatching. Sublethal endpoints used for assessing the developmental effects of dyes included embryo malformations (yolk sac alterations, no rupture of the eggs membrane, defects in gas bladder inflation and skeletal deformities) and hatching success. Hatching was defined as the rupture of the egg membrane, and fully as well as partially hatched larvae were counted as hatched embryos. The distinction between normal and abnormal development of embryos was established according to the zebrafish development descriptions reported by Kimmel et al. [31]. Images of zebrafish at different post-fertilization times were captured using a microscope with digital camera (Moticam 2000, Motic).

\subsection{Criteria validity}

After egg collection, fertilization success was checked and only batches of eggs with a minimum fertilization rate of $80 \%$ were used. Control solutions were also made to confirm the accuracy of the test. 3,4 - Dichloroaniline $(3.7 \mathrm{mg} / \mathrm{L})$ was used as positive control, resulting in $100 \%$ mortality, while more than $90 \%$ survival was observed in the control group (data not shown).

\subsection{Statistical analysis}

One-way ANOVA followed by Dunnett's multiple comparison test was performed, using software package GraphPad Prism 5.0 ${ }^{\circledR}$ (version 5.0, GraphPad Software, San Diego, CA, USA). Each experimental value was compared to its corresponding control. Statistical significance was accepted when the probability of the result assuming the null hypothesis (p) was less than 0.05 . 


\section{RESULTS}

\subsection{Effects on survival and hatching rate}

No significant mortality of the fertilized zebrafish eggs exposed to DB38, RB15, RO16 and VG3 for 8 to 48 hpf was observed in the tested conditions.

No significant differences were observed between the frequencies of hatching induced by the DB38, RB15, and VG3 dyes and the negative control. Only RO16 caused delay or inhibition on the ability of zebrafish embryos to hatch from the chorion, which was observed after $96 \mathrm{hpf}$ at $100 \mathrm{mg} / \mathrm{L}$, and remained significant after 120 and $144 \mathrm{hpf}$ (Figure 2).

\subsection{Malformations}

Embryo malformations such as defects in the gas bladder inflation (Figure 3) have become apparent from the onset of hatching (96 hpf) in embryos exposed to DB38, RO16, and VG3 dyes. In contrast, for RB15 this developmental effect occurred only after 120 hpf (Figure 4).

Larvae from the control groups presented no significant abnormality and had a oval shaped, transparent, and gas-filled bladder, which was easily detected under the microscope (Figure 3A), while embryos exposed to dyes DB38, RO16, RB15, and VG3 presented non-inflated swim bladder, as shown in Figure 3B, using a larvae exposed to DB38 as example.

According to Figure 4, larvae exposed to the highest doses of textile dyes showed defects in gas bladder inflation mainly after $120 \mathrm{hpf}$. However, larvae exposed to DB38 dye presented a failure in the gas bladder inflation from the concentration of 
$6.25 \mathrm{mg} / \mathrm{L}$ at $96 \mathrm{hpf}$. More than $90 \%$ of larvae exposed to DB38 dye at $25 \mathrm{mg} / \mathrm{L}$ presented non-inflated swim bladder.

In addition, other embryo malformations, such as yolk sac alteration and skeletal deformity were observed after exposure of embryos to DB38 and VG3 dyes. DB38 exposure induced curved tail on embryos from $120 \mathrm{hpf}$ in a concentration-dependent way (Figure 5A), whereas VG3 dye caused yolk sac edema (Figure 5B) in zebrafish larvae from $120 \mathrm{hpf}$.

\section{DISCUSSION}

Previous studies have mainly focused on the decolorization of textile dye wastewater $[26,39,40]$, evaluation of genotoxicity/mutagenicity of parent compound and by-products in vivo [7] or in vitro [12-14], as well as toxicity to aquatic organisms such as bioluminescent bacterium, algae, microcrustaceans and fish [4,14,20,23-30]. Once there is no information about the effects of dyes on fish embryos, the toxicity of DB38, RB15, RO16, and VG3 dyes in zebrafish early life stages was determined by the hatching rate, embryo malformations, including defects in the gas bladder inflation, yolk sac alteration and skeletal deformity. Table 1 shows these toxicological endpoints for the evaluation of lethal and sublethal effects of the dyes on zebrafish at $8,24,72,96$, 120, and 144 hpf.

Despite the great public demand for replacement of animal experiments for ethical reasons, industry has searched for alternative testing methods that are less costintensive and less time- and space-consuming [32]. Zebrafish embryos represent an attractive model for studies of developmental toxicity of chemicals both for human and environmental risk assessment, due to its rapid development, easy maintenance in the laboratory, large number of offspring, transparency of embryos and access to 
experimental manipulation [32,41]. Additionally, according to current European Union legislation [42] for the protection of animals used for experimental and other scientific purposes, the use of vertebrate embryo is not regulated, and fish embryos are considered as non-protected life stages and similar to in vitro assays - an alternative to animal testing, despite using whole organisms [43,44]. Zebrafish embryos are also well suited for studies of sublethal effects and toxicity mechanisms. Inclusion of sublethal endpoints in ecotoxicity testing, in addition to lethality, is of great importance since such effects may occur in non-target organisms, with significant impacts on populations or ecosystems [41].

According to the literature, $\mathrm{LC}_{50}$ values of many commercial dyes have been estimated in adult fish at different time intervals. Hormazabal et al. [45] showed that malachite green (MG), a triarylmethane dye, is highly toxic to freshwater fish, in both acute and chronic exposures. Others authors also observed changes in $\mathrm{LC}_{50}$ values of MG in the freshwater catfish Heteropneustes fossilis, at different exposure times, and stated that toxicity increased with exposure time [46]. The results of the present study demonstrated no significant mortality or lethal effect of DB38, RB15, RO16, and VG3 dyes on zebrafish embryos at 8 to $48 \mathrm{hpf}$ in the tested conditions.

Figure 2 shows the effects of RO16 on hatching success of zebrafish embryo. Delayed hatching may be due to an inability of embryos to break the chorion. This result indicates that the $\mathrm{RO} 16$ dye significantly reduced the hatching rate at $100 \mathrm{mg} / \mathrm{L}$ at 96, 120, and 144 hpf $(\mathrm{p}<0.05)$. Recent studies have shown that other environmental contaminants including hexabromocyclododecanes diastereoisomers $(\alpha-\mathrm{HBCD}$ and $\beta$ HBCD) also caused hatching delay in zebrafish embryos [47]. 
Fish are exposed to aquatic toxicants via the delicate respiratory surface of the gills, which comprise over half of the body surface area, and make intimate contact with the surrounding water. Usually, low pollutant concentrations may not result in fish mortality, but may still be toxic to this species [30]. In this study, the most considerable developmental defect caused by textile dyes was the failure of the gas bladder to inflate. The gas bladder, commonly referred as the swim bladder, is a vascularized internal organ found in almost all teleosts. It controls the buoyancy and locomotory movements of fish [48]. The failure in the gas bladder inflation of zebrafish larvae can cause impaired motility, which can ultimately lead to death.

As can be seen in Figure 3, all dyes have induced defects in the swim bladder inflation of zebrafish larvae at 120 and $144 \mathrm{hpf}(\mathrm{p}<0.05)$. Larvae exposed to DB38 dye exhibited a morphological abnormality, which included the development of an abnormal dorsally curved tail. This tail curvature was first observed at $120 \mathrm{hpf}$ in fish exposed to the highest dose of DB38 (25.0 mg/L), and remained significant at $144 \mathrm{hpf}$ (Figure 5A).

Direct Black 38 is a triazo dye based on benzidine, an aromatic amine, classified as a human carcinogen by the IARC [17]. Although the European Community has banned the use of benzidine-based dyes since 2003 [49], these compounds have been detected in several countries, including Mexico [50], India [17], and Brazil [51]. According to Dapson [52], the use of benzidine-based dyes is very common in underdeveloped countries, where ambitions in relation to international trade outweigh concerns about the risks to health and environment. Similar fact was observed with the MG, which has been banned in several countries and was not approved by US Food and Drug Administration, but it is still used in many parts of the world due to its low cost, ready availability and efficacy [29]. 
Yolk sac was another toxicological endpoint analyzed in this study, once it provides nutritive material vital for the movement of larvae, and plays an important role in the early development of zebrafish [48]. Figure 5B shows that the VG3 dye at 100 $\mathrm{mg} / \mathrm{L}$ also induced yolk sac edema in larvae at 120 and $144 \mathrm{hpf}(\mathrm{p}<0.05)$. These results are similar to the findings of Du et al. [47], who found that HBCD diastereoisomers, substances detected in practically all environmental media, caused malformation in zebrafish embryos including yolk sac edema.

\section{CONCLUSION}

In summary, the present results clearly show that the textile dyes DB38, RB15, RO16, and VG3 can affect the embryonic and larval development of zebrafish (Danio rerio) in a dose-dependent manner, based on the delayed hatching of eggs, presence of malformation including defects in gas bladder inflation, yolk sac alteration and skeletal deformity, and thus decreased survivorship. The four textile dyes exhibited different developmental toxicity to zebrafish embryos, and the order of the toxicity was DB38 > $\mathrm{VG} 3>\mathrm{RO} 16>\mathrm{RB} 15$.

It is important to evaluate the toxicity at various trophic levels, in particular with fish. Due to its similarities of vertebrate embryos, zebrafish is used as a model for human and environmental sciences. Therefore, the bioassay with zebrafish embryos can be used as an initial screening test to analyze the toxicity of dyes and to manage dyecontaining effluents, in order to prevent human health risks and minimize impacts on aquatic environments. 


\section{CONFLICT OF INTEREST STATEMENT}

The authors declare there were no conflicting interests. 


\section{ACKNOWLEDGEMENTS}

This research was supported by the Faculty of Pharmaceutical Sciences at Ribeirão Preto - University of São Paulo, Unit of Experimental Toxicology and Ecotoxicology - Barcelona Science Park. The authors also would like to thank the Fundação de Amparo a Pesquisa do Estado de São Paulo (FAPESP) - São Paulo/SP, Brazil, for its financial support and scholarship (Process No. 2013/01509-4 and 2013/01735-4, respectively). 


\section{REFERENCES}

1. Rodríguez-Couto S. 2009. Dye removal by immobilized fungi. Biotechnol Adv $27(3): 227-235$.

2. Welham A. 2000. The theory of dyeing (and the secret of life). J Soc Dyers Colour 116:140-143.

3. Dos Santos AB, Cervantes FJ, Van Lier JB. 2007. Review paper on current technologies for decolourisation of textile wastewaters: Perspectives for anaerobic biotechnology. Bioresour Technol 98(12):2369-2385.

4. Li Y, Shi JQ, Qu RJ, Feng MB, Liu F, Wang M, Wang ZY. 2012. Toxicity assessment on three direct dyes (D-BLL, D-GLN, D-3RNL) using oxidative stress bioassay and quantum parameter calculation. Ecotoxicol Environ Saf 86:132-140.

5. Guendouz S, Khellaf N, Zerdaoui M, Ouchefoun M. 2012. Biosorption of synthetic dyes (Direct Red 89 and Reactive Green 12) as an ecological refining step in textile effluent treatment. Environ Sci Technol Pollut Res Int 20(6):3822-3829.

6. Mansour HB, Houas I, Montassar F, Ghedira K, Barillier D, Mosrati R, ChekirGhedira L. 2012. Alteration of in vitro and acute in vivo toxicity of textile dyeing wastewater after chemical and biological remediation. Environ Sci Pollut Res Int 19(7):2634-2643.

7. Rajaguru P, Fairbairn LJ, Ashby J, Willington MA, Turner S, Woolford LA, Chinnasamy N, Rafferty JA. 1999. Genotoxicity studies on the azo dye Direct Red 2 using the in vivo mouse bone marrow micronucleus test. Mutat Res 444(1):175-180.

8. Gurav AA, Ghosh JS, Kulkarni GS. 2011. Decolorization of anthroquinone based dye Vat Red 10 by Pseudomonas desmolyticum NCIM 2112 and Galactomyces geotrichum MTCC 1360. Int J Biotechnol and Mol Biol Res 2(6):93-97. 
9. Robinson T, Mcmullan G, Marchant R, Nigam P. 2001. Remediation of dyes in textile effluent: acritical review on current treatment technologies with a proposed alternative. Bioresour Technol 77(3):247-255.

10. Chung KT, Stevens SE. 1993. Degradation azo dyes by environmental microorganisms and helminths. Environ Toxicol Chem 12(11):2121-2132.

11. Bae JS, Freeman HS, Warren SH, Claxton LD. 2006. Evaluation of new 2,2'dimethyl-5,5'-dipropoxybenzidine- and 3,3'-dipropoxybenzidine-based direct dye analogs for mutagenic activity by use of the Salmonella/mammalian mutagenicity assay. Mutat Res 603(2):173-185.

12. Chequer FMD, Angeli JPF, Ferraz ERA, Tsuboy MS, Marcarini JC, Mantovani MS, Oliveira DP. 2009. The azo dyes Disperse Red 1 and Disperse Orange 1 increase the micronuclei frequencies in human lymphocytes and in HepG2 cells. Mutat Res 676(1-2):83-86.

13. Oliveira GAR, Ferraz ERA, Chequer FMD, Grando MD, Angeli JPF, Tsuboy MS, Marcarini JC, Mantovani MS, Osugi ME, Lizier TM, Zanoni MVB, Oliveira DP. 2010. Chlorination treatment of aqueous samples reduces, but does not eliminate, the mutagenic effect of the azo dyes Disperse Red 1, Disperse Red 13 and Disperse Orange 1. Mutat Res 703(2):200-208.

14. Ferraz ERA, Umbuzeiro GA, De-Almeida G, Caloto-Oliveira A, Chequer FMD, Zanoni MVB, Dorta DJ, Oliveira DP. 2011. Differential toxicity of Disperse Red 1 and Disperse Red 13 in the Ames test, HepG2 cytotoxicity assay, and Daphnia acute toxicity test. Environ Toxicol 26:489-97.

15. IARC, International Agency for Research on Cancer. Direct Black 38. 1982. Monogr Eval Carcinog Risk Chem Hum 29:295-310. 
16. NTP, National Toxicology Program. 2011. Benzidine and dyes metabolized to benzidine: dyes metabolized to benzidine (benzidine dye class). Report on Carcinogens, $12^{\text {th }}$ edition, 64-66.

17. Mathur N, Bhatnagar P, Bakre P. 2005. Assessing mutagenicity of textile dyes from Pali (Rajasthan) using Ames bioassay. Appl Ecol Environ Res 4(1):111-118.

18. Rajaguru P, Kalpana R, Hema A, Suba S, Baskarasethupathi B, Kumar PA, Kalaiselvi K. 2001. Genotoxicity of some sulfur dyes on tadpoles (Rana hexadactyla) measured using the comet assay. Environ Mol Mutagen 38(4), 316-322.

19. Osugi ME, Umbuzeiro GA, De Castro FJ, Zanoni MV. 2006. Photoelectrocatalytic oxidation of remazol turquoise blue and toxicological assessment of its oxidation products. J Hazard Mater 137(2):871-877.

20. Novotný C, Dias N, Kapanen A, Malachová K, Vándrovcová M, Itävaara M, Lima N. 2006. Comparative use of bacterial, algal and protozoan tests to study toxicity of azo- and anthraquinone dyes. Chemosphere 63:1436-1442.

21. Balan DS, Monteiro RT. 2001. Decolorization of textile indigo dye by ligninolytic fungi. J Biotechnol 89(2-3):141-145.

22. Chaari I, Jamoussi F. 2011. Application of activated carbon for vat dye removal from aqueous solution. J Appl Sci Environ Sanit 6(3):247-256.

23. Luna LA, Silva TH, Nogueira RF, Kummrow F, Umbuzeiro GA. 2014. Aquatic toxicity of dyes before and after photo-Fenton treatment. J Hazard Mater 276:332338.

24. Grinevicius VM, Geremias R, Laus R, Bettega KF, Laranjeiras MC, Fávere VT, Wilhelm Filho D, Pedrosa RC. 2009. Textile effluents induce biomarkers of acute toxicity, oxidative stress, and genotoxicity. Arch Environ Contam Toxicol 57(2):307314. 
25. Leme DM, Oliveira GAR, Meireles G, Brito LB, Rodrigues LB, Oliveira DP. 2014. Eco- and geno-toxicological assessments of two reactive textile dyes. $J$ Toxicol Environ Health A, in press.

26. Frijters CT, Vos RH, Scheffer G, Mulder R. 2006. Decolorizing and detoxifying textile wastewater, containing both soluble and insoluble dyes, in a full scale combined anaerobic/aerobic system. Water Res 40(6):1249-1257.

27. Bae JS, Freeman HS. 2007. Aquatic toxicity evaluation of new direct dyes to the Daphnia magna. Dyes Pigments 73(1):81-85.

28. Verma Y. 2008. Acute toxicity assessment of textile dyes and textile and dye industrial effluents using Daphnia magna bioassay. Toxicol Ind Health 24(7):491500.

29. Srivastava S, Sinha R, Roy D. 2004. Toxicological effects of malachite green. Aquat Toxicol 66(3):319-29.

30. Soni P, Sharma S, Sharma S, Kumar S, Sharma KP. 2006. A comparative study on the toxic effects of textile dye wastewaters (untreated and treated) on mortality and $\mathrm{RBC}$ of a freshwater fish Gambusia affinis (Baird and Gerard). J Environ Biol 27(4):623-628.

31. Kimmel CB, Ballard WW, Kimmel SR, Ullmann B, Schilling TF. 1995. Stages of embryonic development of the zebrafish. Dev Dyn 203(3):253-310.

32. Scholz S, Fischer S, Gündel U, Küster E, Luckenbach T, Voelker D. 2008. The zebrafish embryo model in environmental risk assessment--applications beyond acute toxicity testing. Environ Sci Pollut Res Int 15(5):394-404.

33. Lammer E, Carr GJ, Wendler K, Rawlings JM, Belanger SE, Braunbeck T. 2009. Is the fish embryo toxicity test (FET) with the zebrafish (Danio rerio) a potential alternative for the fish acute toxicity test? Comp Biochem Physiol C 149:196-209. 
34. Hagenaars A, Vergauwen L, De Coen W, Knapen D. 2011. Structure-activity relationship assessment of four perfluorinated chemicals using a prolonged zebrafish early life stage test. Chemosphere 82(5):764-772.

35. ISO, International Organization for Standardization. 1996. ISO-7346-1:Water quality: determination of the acute lethal toxicity of substances to a freshwater fish [Brachidanio rerio Hamilton: Buchanan (Teleostei, Cyprinidae)]: part 1: static method. Geneve, Switzerland.

36. OECD, Organization for Economic Co-Operation and Development. 2006. Fish Embryo Toxicity Test.

37. Nagel R. 2002. DarT: The embryo test with the Zebrafish Danio rerio - a general model in ecotoxicology and toxicology. ALTEX 19(1):38-48.

38. OECD, Organization for Economic Co-Operation and Development. 1998. Test No. 212: Fish, Short-term Toxicity Test on Embryo and Sac-Fry Stages.

39. Isik M, Sponza DT. 2004. Monitoring of toxicity and intermediates of C.I. Direct Black 38 azo dye through decolorization in an anaerobic/aerobic sequential reactor system. J Hazard Mater 114(1-3):29-39.

40. Malachova K, Rybkova Z, Sezimova H, Cerven J, Novotny C. 2013. Biodegradation and detoxification potential of rotating biological contactor (RBC) with Irpex lacteus for remediation of dye-containing wastewater. Water Res 47(19):7143-7148.

41. Carlsson G, Patring J, Kreuger J, Norrgren L, Oskarsson A. 2013. Toxicity of 15 veterinary pharmaceuticals in zebrafish (Danio rerio) embryos. Aquat Toxicol 126:30-41.

42. Directive 2010/63/EU of the European Parliament and of the Council on the protection of animals used for scientific purposes. 2010. Official Journal of the European Union, L276:33-79, September 22, 2010. 
43. Strähle U, Scholz S, Geisler R, Greiner P, Hollert H, Rastegar S, Schumacher A, Selderslaghs I, Weiss C, Witters H, Braunbeck T. 2012. Zebrafish Embryos as an alternative to animal experiments--a commentary on the definition of the onset of protected life stages in animal welfare regulations. Reprod Toxicol 33(20):128-132.

44. Teixidó E, Piqué E, Gómez-Catalán J, Llobet J.M. 2013. Assessment of developmental delay in the zebrafish embryo teratogenicity assay. Toxicol In Vitro $27(1): 469-478$.

45. Hormazabal V, Steffenak I, Yndestad M. 1992. A time and cost-effective assay for the determination of residues of malachite green in fish tissues by HPLC. J Liquid Chromatogr 15(12):2035-2044.

46. Srivastava SJ, Singh, ND, Srivastava AK, Sinha R. 1995. Acute toxicity of malachite green and its effects on certain blood parameters of a catfish, Heteropneustes fossilis. Aquat Toxicol 31:241-247.

47. Du M, Zhang D, Yan C, Zhang X. 2012. Developmental toxicity evaluation of three hexabromocyclododecane diastereoisomers on zebrafish embryos. Aquat Toxicol 112-113:1-10.

48. Li J, Liang Y, Zhang X, Lu J, Zhang J, Ruan T, Zhou Q, Jiang G. 2011. Impaired gas bladder inflation in zebrafish exposed to a novel heterocyclic brominated flame retardant tris(2,3-dibromopropyl) isocyanurate. Environ Sci Technol 45(22):97509757.

49. Directive 2002/61/EC of the European Parliament and of the Council on the marketing and use of certain dangerous substances and preparations (azocolourants). 2002. Official Journal of the European Union, L243/15, July 19, 2002. 
50. Bandala ER, Pelaez MA, García-Lopez J, Salgado MJ, Moeller G. 2008. Photocatalytic decolourisation of synthetic and real textile wastewater containing benzidine-based azo dyes. Chem Eng Process 47:169-176.

51. Sauer TP, Casaril L, Oberziner AL, José HJ, Moreira RF. 2006. Advanced oxidation processes applied to tannery wastewater containing Direct Black 38--elimination and degradation kinetics. J Hazard Mater 135(1-3):274-279.

52. Dapson RW. 2009. Benzidine-based dyes: effects of industrial practices, regulations, and world trade on the biological stains market. Biotech Histochem 84(3):95-100. 


\section{FIGURE LEGENDS}

Figure 1: The chemical structures of the dyes Direct Black 38 (A), Reactive Blue 15 (B), Reactive Orange 16 (C) and Vat Green 3 (D).

Figure 2. Effects of Reactive Orange 16 on hatching success of zebrafish embryo. Bars represent the mean $\pm \operatorname{SEM}(n=3) .{ }^{*} \mathrm{p}<0.05$ statistically different from the respective negative control.

Figure 3. Effects of textile dyes on swim bladder morphology during development of zebrafih larvae. (A) Photomicrographs of left lateral views of larvae with inflated swim bladder from control group (B) larvae with uninflated swim bladder from experimental group (Direct Black 38) at $144 \mathrm{hpf}$.

Figure 4. Effects of the Direct Black 38, Reactive Blue 15, Reactive Orange 16 and Vat Green 3 dyes on gas bladder of zebrafish larvae. Bar represent the mean $\pm \operatorname{SEM}(n=3)$. ${ }^{*} \mathrm{p}<0.05$ and ${ }^{* *} \mathrm{p}<0.01$ statistically different from the respective negative control.

Figure 5. Skeletal deformity and yolk sac alteration caused by Direct Black 38 (A) and Vat Green 3 dyes (B) on zebrafish larvae, respectively. Bar represent the mean \pm SEM of three tests. ${ }^{*} \mathrm{p}<0.05$ statistically different from the respective negative control. 
Table 1. Toxicological endpoints for the evaluation of lethal and sublethal effects of the textile dyes on zebrafish embryos, adapted from Hagenaars et al. [34] and Nagel [37].

\begin{tabular}{|c|c|c|c|c|c|c|c|}
\hline \multirow{2}{*}{$\begin{array}{l}\text { Toxicological } \\
\text { Endpoints }\end{array}$} & \multicolumn{7}{|c|}{ Exposure time (hpf) } \\
\hline & 8 & 24 & 48 & 72 & 96 & 120 & 144 \\
\hline \multicolumn{8}{|l|}{ Lethal } \\
\hline Coagulation & $X$ & $X$ & $X$ & $X$ & $X$ & $X$ & $X$ \\
\hline Tail detachment & & $X$ & $\mathrm{X}$ & $\mathrm{X}$ & $\mathrm{X}$ & $X$ & $X$ \\
\hline No somites & & $\mathrm{X}$ & $\mathrm{X}$ & $\mathrm{X}$ & $\mathrm{X}$ & $X$ & $X$ \\
\hline No heart beat & & & $\mathrm{X}$ & $\mathrm{X}$ & $\mathrm{X}$ & $\mathrm{X}$ & $\mathrm{X}$ \\
\hline \multicolumn{8}{|l|}{ Sublethal } \\
\hline Yolk sac edema & & & & $\mathrm{X}$ & $\mathrm{X}$ & $X$ & $\mathrm{X}$ \\
\hline Gas bladder deffect & & & & $\mathrm{X}$ & $\mathrm{X}$ & $\mathrm{X}$ & $\mathrm{X}$ \\
\hline Skeletal deformities & & & & $\mathrm{X}$ & $\mathrm{X}$ & $X$ & $\mathrm{X}$ \\
\hline Hatching rate & & & & $\mathrm{X}$ & $\mathrm{X}$ & $X$ & $X$ \\
\hline
\end{tabular}


Figure 1.

(A)
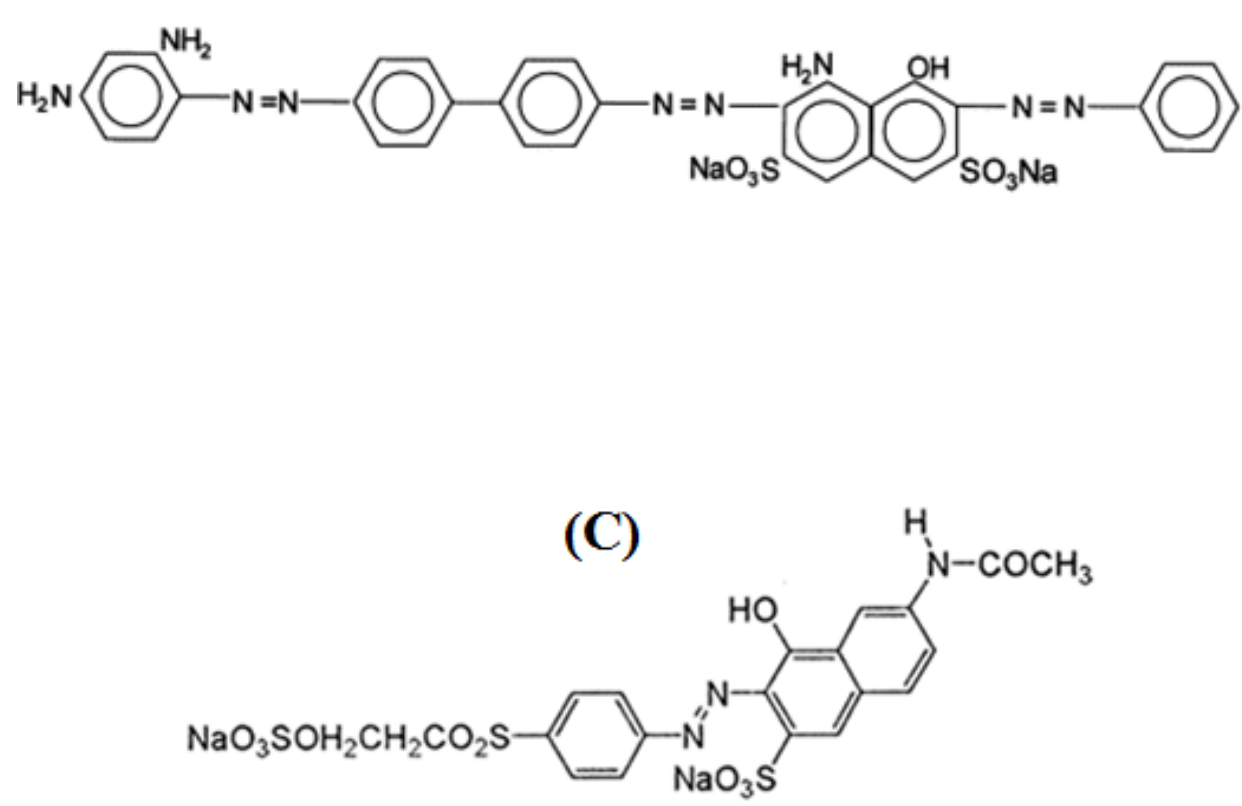

(B)

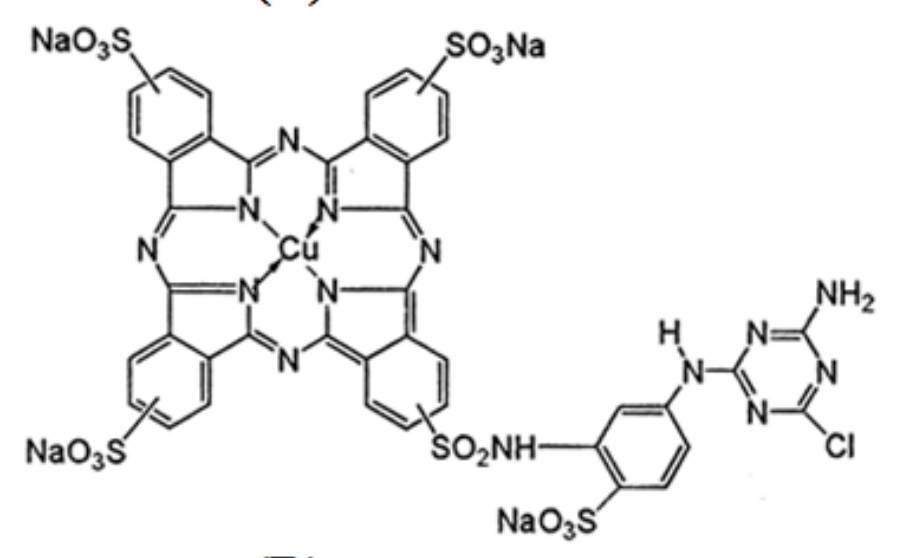

(D)

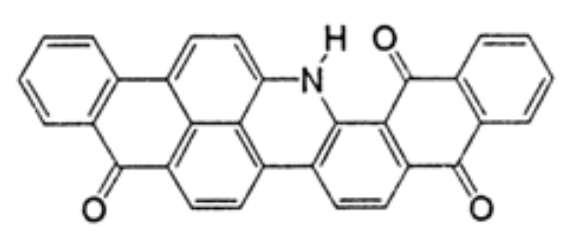


Figure 2.

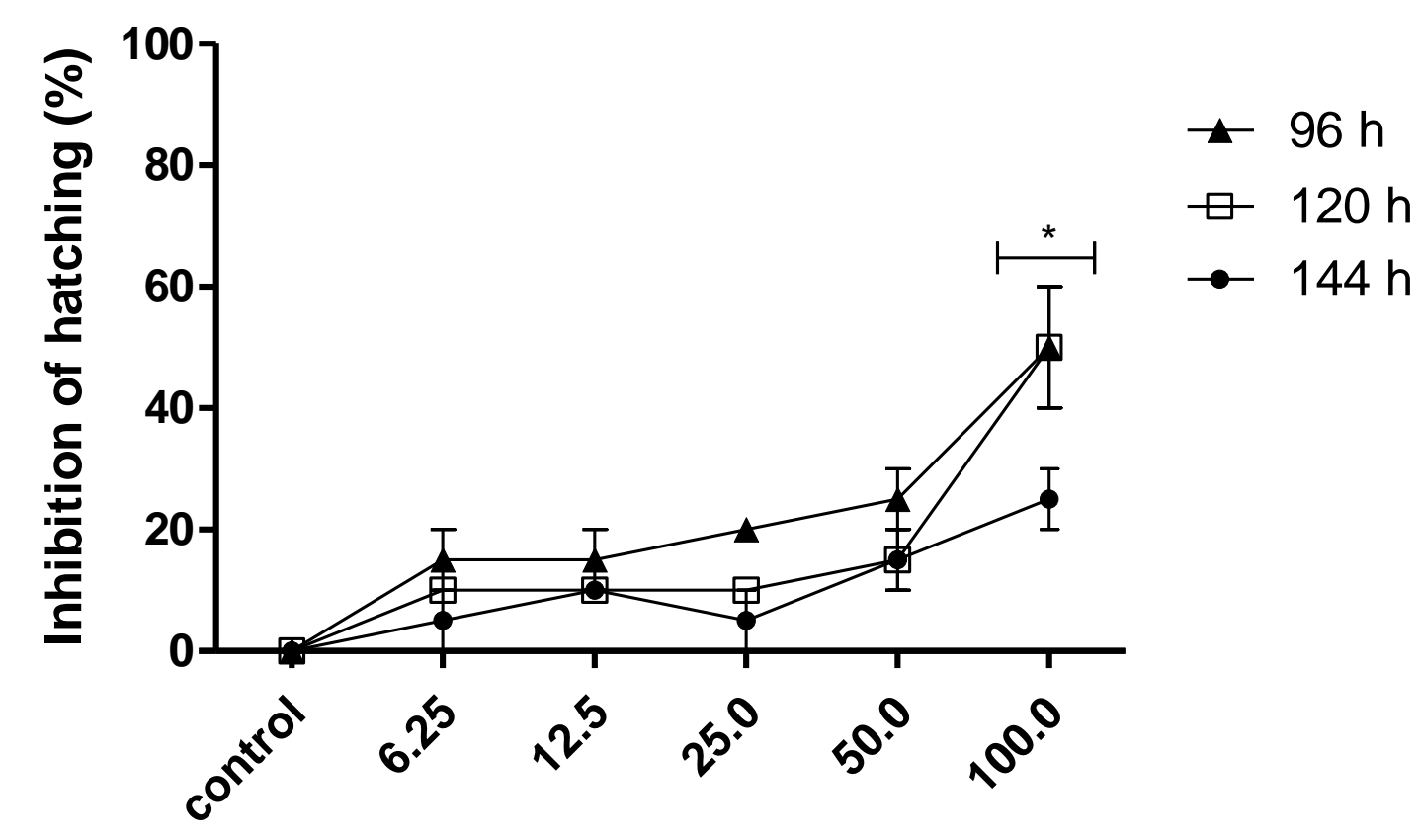

Reactive Orange 16 (mg/L) 
Figure 3.
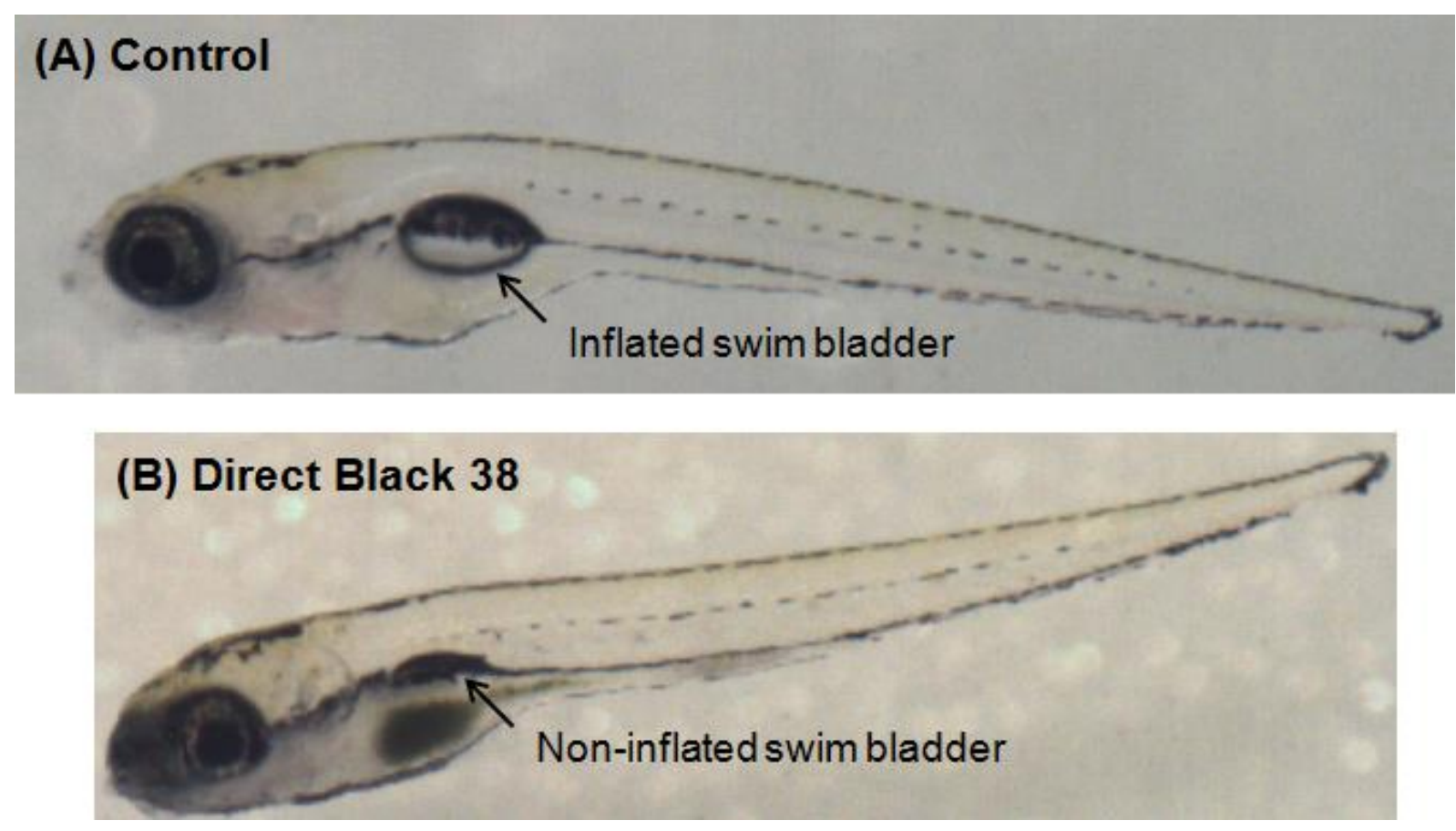

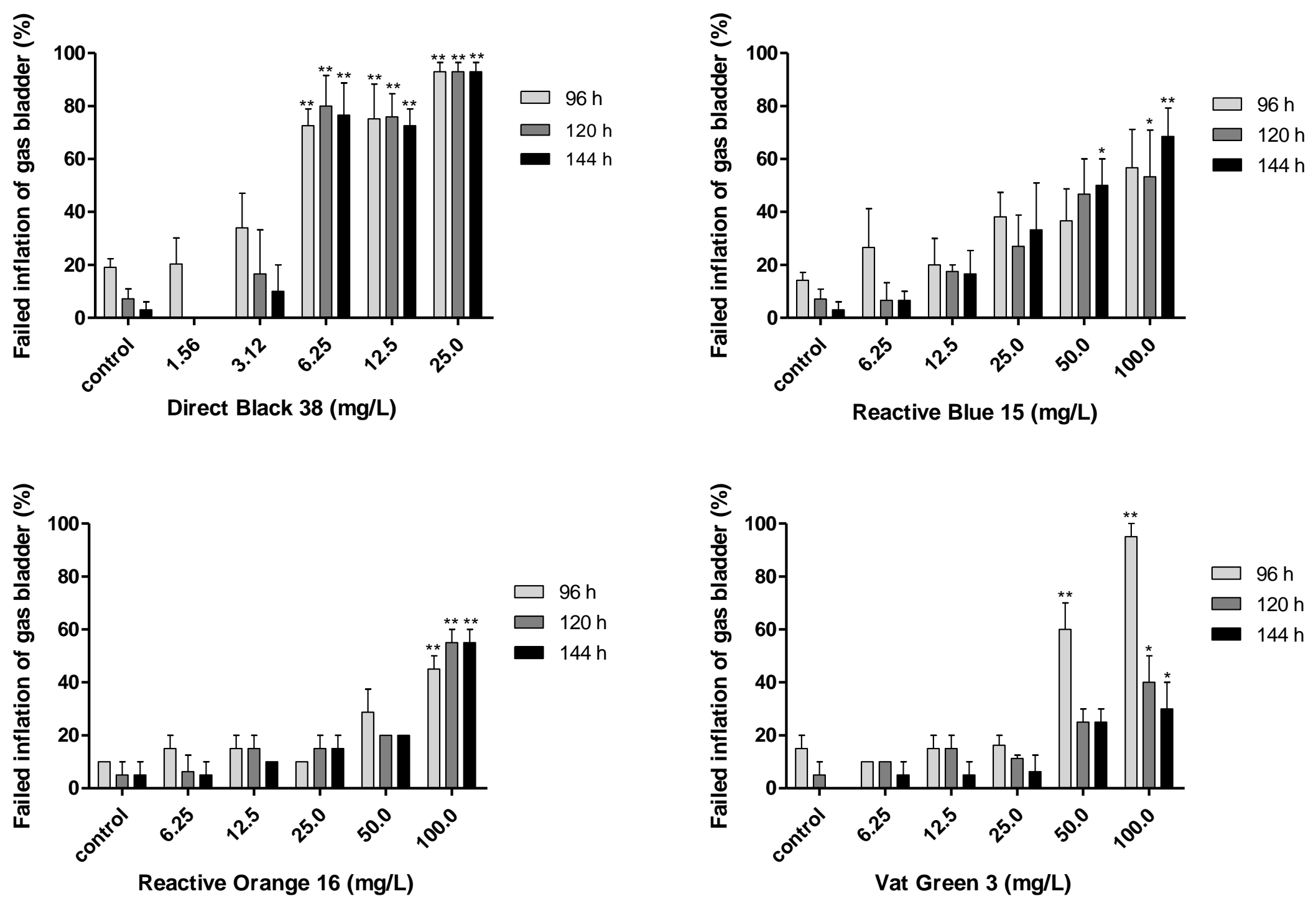


\section{Figure 5.}

(A)

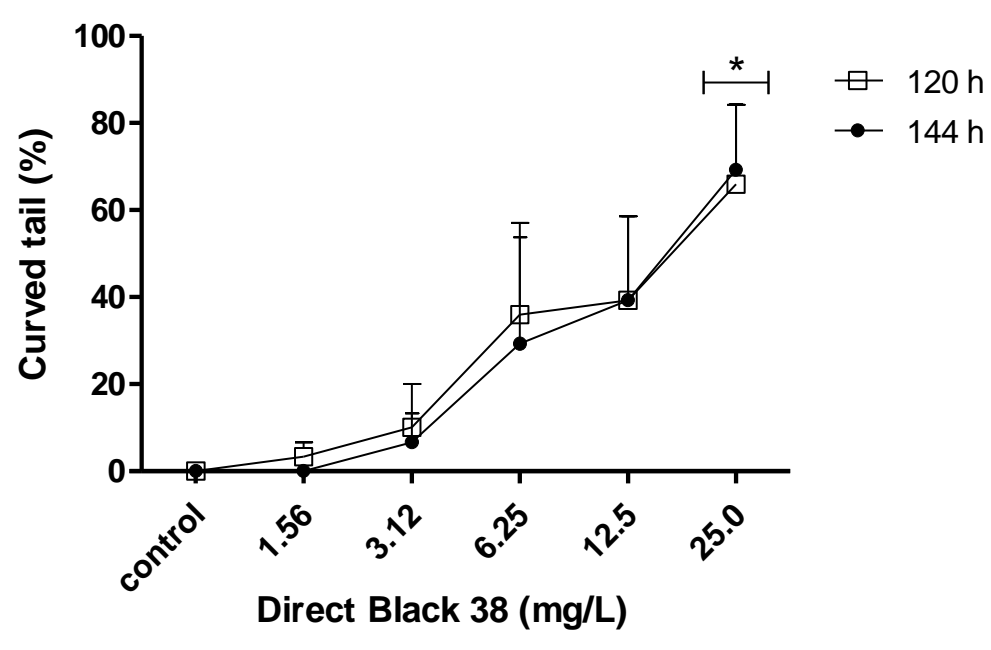

(B)

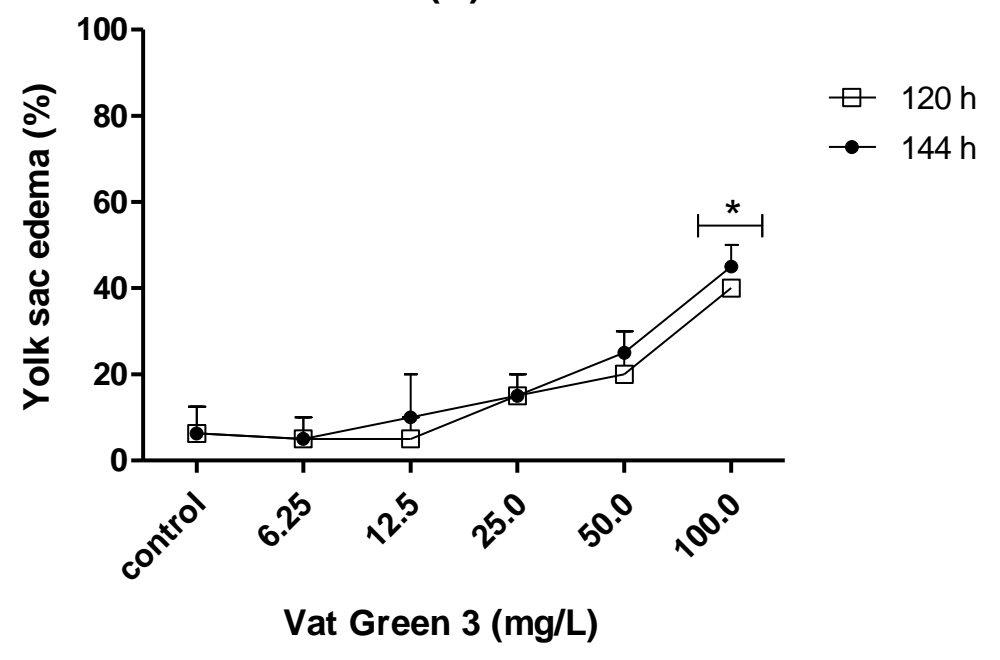

